Article

\title{
The Bonding Mechanism of the Micro-Interface of Polymer Coated Steel
}

\author{
Jiyang Liu *, Qingdong Zhang *, Boyang Zhang and Mingyang Yu \\ School of Mechanical Engineering, University of Science and Technology, Beijing 100083, China; \\ zhangby@ustb.edu.cn (B.Z.); 15600990167@163.com (M.Y.) \\ * Correspondence: b20170270@xs.ustb.edu.cn (J.L.); zhang_qd@me.ustb.edu.cn (Q.Z.)
}

Received: 16 November 2020; Accepted: 15 December 2020; Published: 19 December 2020

\begin{abstract}
As food and beverages require more and more green and safe packaging products, the emergence of polymer coated steel (PCS) has been promoted. PCS is a layered composite strip made of metal and polymer. To probe the bonding mechanism of PCS micro-interface, the substrate tin-free steel (TFS) was physically characterized by SEM and XPS, and cladding polyethylene terephthalate (PET) was simulated by first-principles methods of quantum mechanics (QM). We used COMPASS force field for molecular dynamics (MD) simulation. XPS pointed out that the element composition of TFS surface coating is $\mathrm{Cr}(\mathrm{OH})_{3}, \mathrm{Cr}_{2} \mathrm{O}_{3}$ and $\mathrm{CrO}_{3}$. The calculation results of MD and QM indicate that the chromium oxide and PET molecules compound in the form of acid-base interaction. The binding energies of $\mathrm{Cr}_{2} \mathrm{O}_{3}$ (110), (200), and (211) with PET molecules are $-13.07 \mathrm{eV}$, $-2.74 \mathrm{eV}$, and $-2.37 \mathrm{eV}$, respectively. We established a $\mathrm{Cr}_{2} \mathrm{O}_{3}$ (200) model with different hydroxyl concentrations. It is proposed that the oxygen atom in $\mathrm{C}=\mathrm{O}$ in the PET molecule combines with $-\mathrm{OH}$ on the surface of TFS to form a hydrogen bond. The binding energy of the PCS interface increases with the increase of the surface hydroxyl concentration of the TFS. It provides theoretical guidance and reference significance for the research on the bonding mechanism of PCS.
\end{abstract}

Keywords: polymer coated steel; micro-interface; bonding mechanism; molecular dynamics (MD); quantum mechanics $(\mathrm{QM})$

\section{Introduction}

Polymer coated steel (PCS) a layered metal polymer composite strip mainly used in the food packaging industry [1]. It has good mechanical properties, corrosion resistance, and longer preservation of food taste, and is widely used in high-grade beverage and food packaging. For food-grade packaging material, the technical requirements are increasing [2,3]. At present, Europe, the United States, Japan, South Korea, and other countries have carried out much research on PCS materials, including the PCS coating process $[4,5]$, coating quality characterization $[6,7]$, heat transfer during the coating process [8], PCS heat treatment [9], PCS application [10], film surface modification [11] and so on. In this paper, the micro-interface bonding mechanism of PCS is studied by the method of coating experiment combined with simulation. An effective method to improve the quality of the film is proposed.

PCS materials were first developed and applied by Japan in the 1980s. Later, European countries and the United States also carried out related research. PCS is a metal-polymer composite material prepared by using chrome-plated steel strip as the base material and polymer film as the covering material through a roll-pressing hot-melt film process. Commonly used polymer films are polyethylene terephthalate (PET), polyethylene (PE), polypropylene (PP), etc., among which food-grade PET is the most common material [12,13].

The adhesion and mutual bonding of polymer materials on metal surfaces is an important research direction in the field of surface science [14-16].At present, there are four main types of metal and 
non-metal adhesion mechanisms generally recognized in the world: mechanical interlocking theory, electronic theory, diffusion theory, and adsorption theory [17].

Regarding the micro-combination mechanism of the PCS interface, most scholars in the world agree with the hydrogen bond combination theory proposed by Tanaka in 1987, which belongs to one of the above adsorption theories [18]. During the lamination process, the $\mathrm{O}$ in the carbonyl group in the polymer film combines with the $\mathrm{H}$ in the $-\mathrm{OH}$ on the TFS surface to form a hydrogen bond, but the theoretical and experimental basis for the formation of hydrogen bonds is not mentioned. Komai [19] pointed out that the hydrated chromium oxide on the surface of the TFS and the polymer film in the micro-interface of the PCS are connected in the form of hydrogen bonds. The hydrated chromium oxide acts as a proton acceptor to provide the $-\mathrm{OH}$ required to form hydrogen bonds. The proton donor provides -O. Zumelzu [20] proposed that the metal/polymer interface recombination mechanism can also be explained by another model, that is, the acid-base interaction mechanism, in which the oxygen atoms in the hydroxyl or benzene ring in PET share their electrons with chromium. In summary, there are two recombination mechanisms at the microscopic interface of PCS: hydrogen bond recombination and acid-base interaction mechanism. Previous studies have made important contributions to the study of the interface bonding mechanism of PCS. However, with the development of science and technology, the use of advanced experimental equipment and calculation methods to quantitatively describe the bonding process of the PCS micro-interface is a direction that still needs to be studied in the PCS field.

With the substantial improvement of computer performance, computer simulation technology has become a powerful tool for us to study the micro-scale of materials. According to previous research, the first principles of quantum mechanics (QM) and molecular dynamics (MD) have become advantageous tools for studying the interaction mechanism between metals and non-metals [21-24]. $\mathrm{MD}$ can simulate the interaction law between atoms in a defined complex system on the atomic scale [25-28]. QM can study the motion law of microscopic particles in the material world. Using first principles to study the principle of interaction between atomic nuclei and electronic components is an effective method. Seunghwa [29] used molecular dynamics (MD) simulation combined with finite element analysis (FEA) to study the mechanical behavior of oxygen-functionalized single-layer graphene/polyethylene (PE) nanocomposites. Ghasem Bahlakeh [30] used MD and QM methods to calculate the interfacial interaction mechanism between $\mathrm{FeO}, \mathrm{Fe}_{3} \mathrm{O}_{4}$, and $\mathrm{Fe}_{2} \mathrm{O}_{3}$ and epoxy resin. By establishing and simulating the interaction law between the hydroxylated $\mathrm{Fe}_{3} \mathrm{O}_{4}$ surface and epoxy resin, it is proposed that increasing the concentration of hydroxyl on the surface of iron oxide can improve the interface bonding strength.

In this paper, from the experimental point of view, the chemical composition of the TFS surface coating on the coated iron substrate was measured by XPS, and then the modeling and simulation were carried out. The bonding process of PET and chromium oxide on the micro interface of PCS was studied by using the first principles method of molecular dynamics and quantum mechanics. In order to comprehensively evaluate the composite mechanism between chromium oxide and PET, three surface models of chromium oxide with different crystal face indexes were established, the binding energy between them and PET was calculated, and the binding modes of the three surfaces with PET were analyzed [31]. At the same time, the surface model of chromium oxide with different hydroxyl concentration was established to analyze the combination mode of hydroxyl and PET and the change rule of binding energy with the increase of hydroxyl concentration. The simulation results in this paper provide theoretical guidance for the study of the interface recombination mechanism of PCS. From the perspective of molecular dynamics and quantum mechanics, the hydrogen bonding and acid-base interaction between PET and TFS are described, which confirms and explains the hydrogen bond recombination theory and acid-base interaction theory proposed by predecessors. It provides a reference for the future research of PCS. 


\section{Experiment and Methods}

\subsection{Sample Preparation}

The PET film used in the preparation of PCS comes from the China Baowu Steel Group. The TFS comes from Shanghai Yigang Cangchu Co., Ltd. Laminating equipment (Laminator equipment, Shanghai Lianjing Co., Ltd., Shanghai, China) is used for the coating test of TFS and PET. The roll pressing and hot fusion coating process of PCS is shown in Figure 1. The PET film and TFS are coated under the double pressure of the heating roller and the silicone roller. During the laminating process, the heating roller acts as a heat source to continuously provide heat to the TFS. The TFS transfers the heat to the PET film and then to the silicone roller. The silicone roller maintains a constant temperature under the action of the cooling roller. Therefore, under the dual effects of the heating of the TFS and the cooling of the silicone roller, a temperature gradient occurs inside the PET along the thickness direction, forming a partial melting [32]. The PET film was completely melted on the side near the TFS, but not on the side near the silicone roller. After the PET film and TFS leave the heating roller and the silicone roller, the PET film is quickly cooled with a cooling liquid to quickly solidify the melted part of the PET to avoid recrystallization of the PET. The final preparation is the PCS material, as shown in Figure 2 [33]. Experimental conditions used for the film coating were a heating roller temperature of $500 \mathrm{~K}$, plus coating speed of $15 \mathrm{~m} / \mathrm{min}$; the pressure roller is coated $1000 \mathrm{~N}$.

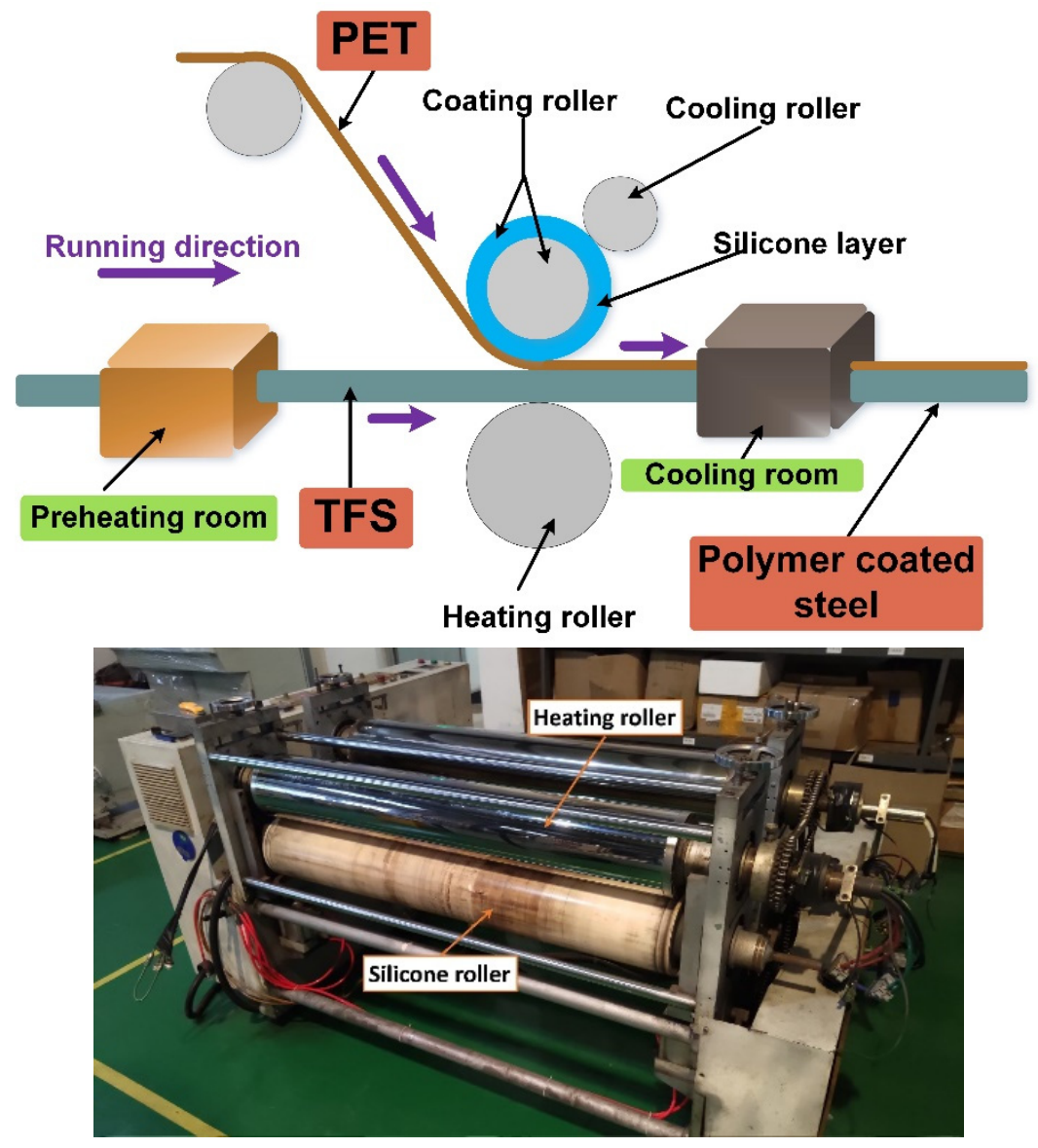

Figure 1. Equipment diagram and schematic diagram of the coating process.

\subsection{XPS and SEM}

The chemical elements and composition of the chromium plating layer on the surface of TFS was carried out using X-ray photoelectron spectroscopy (XPS, Thermo Fisher Scientific ESCALAB 250Xi, Waltham, MA, USA). The thickness of TFS is $0.18 \mathrm{~mm}$, as shown in Figure 3 . The test area of the 
sample is $10 \mathrm{~mm} \times 10 \mathrm{~mm}$. Firstly, the type and concentration of elements on the surface of the TFS are measured, and then the spectrum is fitted with XPSPEAK software to infer the main components of the coating on the surface of the TFS.

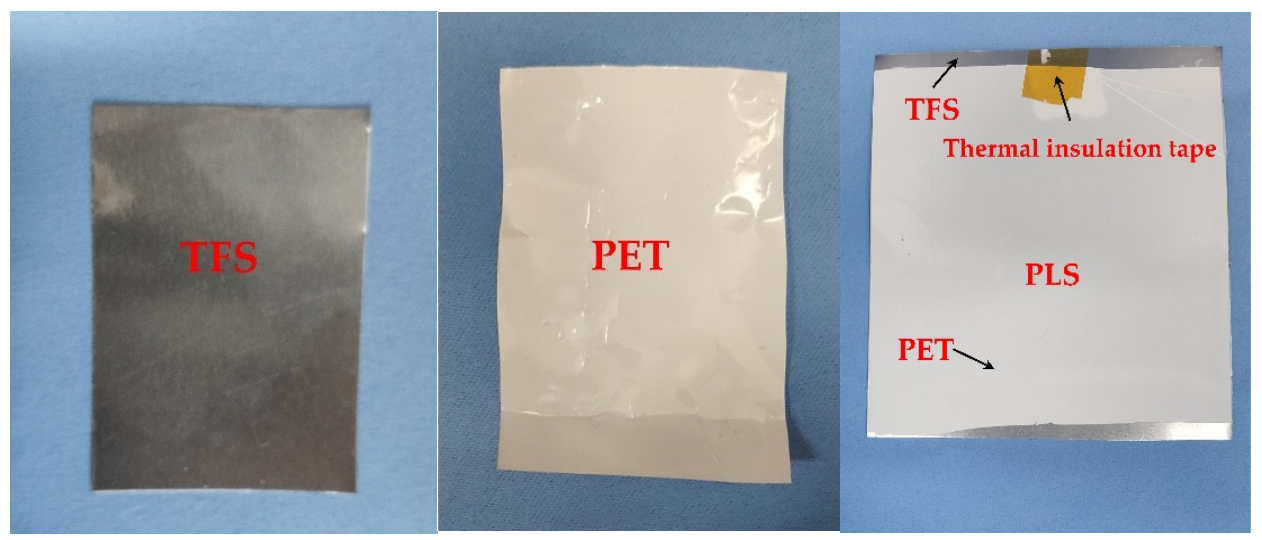

Figure 2. Raw materials and polymer coated steel (PCS) samples.

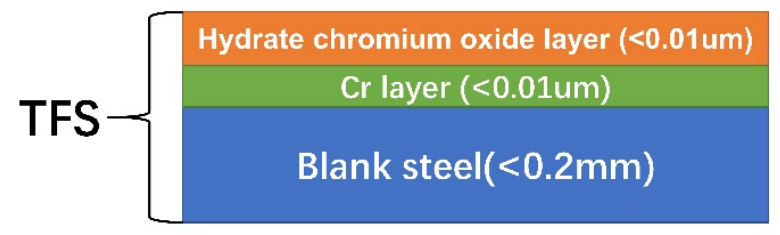

Figure 3. Schematic diagram of the tin free steel (TFS) surface coating structure.

The morphology and microstructure of the TFS surface and blank steel was investigated by a scanning electron microscope (SEM-EDS, ZEISS Gemini 500, Carl Zeiss, Germany). The uniformity of the TFS surface coating was determined by comparing the SEM scan images of the TFS and blank steel. Line scan analysis of the two samples was performed using an EDS analyzer attached to the SEM. The thickness of the TFS and blank steel is approximately $0.18 \mathrm{~mm}$ and the size of the two samples is $10 \mathrm{~mm} \times 10 \mathrm{~mm}$.

\section{3. $M D$ and $Q M$ Simulation}

\subsubsection{PET and the TFS Model}

The polymer films commonly used in PCS materials mainly include polyethylene terephthalate (PET), polyethylene (PE), polypropylene (PP), etc., of which PET is the most common. In this paper, PET was selected as the coated film for research [34]. According to the principle of PCS coating, the PET film undergoes a transition from a highly elastic state to a viscous fluid state to a molten state under the action of heating on the surface of the substrate. Among them, the activity of the PET molecular segments within the material gradually increases with the increase in temperature, and the PET molecules in the molten state are combined with the surface of the substrate through hydrogen bonds [35]. According to the PET molecular formula, a PET molecular model was established using material studio software, as shown in Figure 4.

The substrate TFS used for PCS is prepared by simultaneously electroplating metallic chromium and chromium hydrated oxide on the surface of ordinary strip steel using the one-liquid method or two-liquid method [36,37]. Figure 3 shows the coating structure of the TFS surface. The surface of blank steel has a metal chromium layer with a thickness of less than $0.01 \mathrm{um}$, and then there is a layer of hydrate chromium oxide layers with a thickness of less than $0.01 \mathrm{um}$ on the metal chromium layer. Therefore, the interface bonding mechanism of PCS is the combination of hydrogen chromium oxide layers and PET $[1,20]$. 

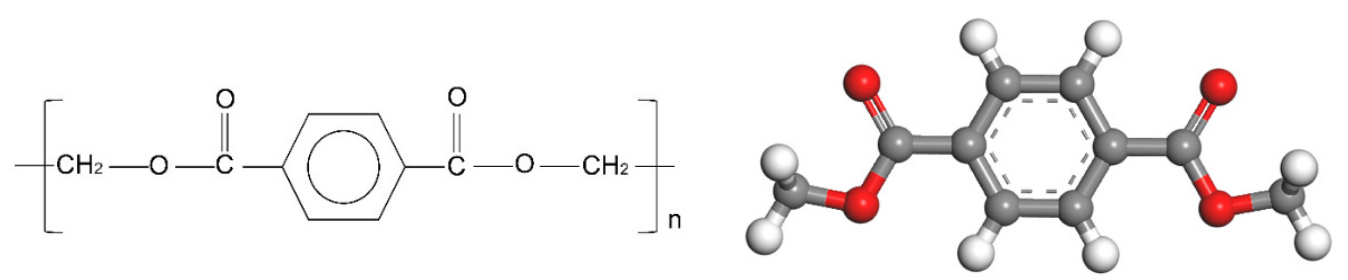

Figure 4. Polyethylene terephthalate (PET) molecular formula and model diagram (white is $\mathrm{H}$ atom, red is $\mathrm{O}$ atom, gray is $\mathrm{C}$ atom).

XPS results show that the main components of hydrogen chromium oxide layers are $\mathrm{Cr}_{2} \mathrm{O}_{3}$ and a large number of bound water molecules. Therefore, a $\mathrm{Cr}_{2} \mathrm{O}_{3}$ surface model with a (110), (200), and (211) crystal face index and $\mathrm{Cr}_{2} \mathrm{O}_{3}$ surface with different hydroxyl concentration were established, respectively. The $\mathrm{Cr}_{2} \mathrm{O}_{3}$ model is taken from the database in Materials Studio 8.0. The lattice constants [38,39] are $\mathrm{a}=\mathrm{b}=4.9589 \AA, \mathrm{c}=13.59308 \AA, \alpha=\beta=90^{\circ}, \gamma=120^{\circ}$, and the cleave surface tool is used to cut out $\mathrm{Cr}_{2} \mathrm{O}_{3}$ (110); the three structural models of $\mathrm{Cr}_{2} \mathrm{O}_{3}$ (200) and $\mathrm{Cr}_{2} \mathrm{O}_{3}$ (211) are respectively set at $13.156 \AA, 21.355 \AA$, and $13.79 \AA$ in thickness.

In order to more accurately simulate the interaction between the chromium oxide and PET molecular chains, the three models generated were enlarged in parallel to the $\mathrm{x}$ and $\mathrm{y}$ directions, and the three models used periodic boundaries in the three coordinate axis directions. In order to ensure that the PET molecules only interact with the upper surface of chromium oxide, a $50 \AA$ vacuum layer is placed vertically above the three upper surfaces [40]. As shown in Figure 5, the final dimensions of the $\mathrm{Cr}_{2} \mathrm{O}_{3}(110), \mathrm{Cr}_{2} \mathrm{O}_{3}(200)$, and $\mathrm{Cr}_{2} \mathrm{O}_{3}$ (211) models are $58.42 \times 53.60 \times 63.36,59.51 \times 54.37 \times 60.17$, and $56.37 \times 53.60 \times 62.82$.

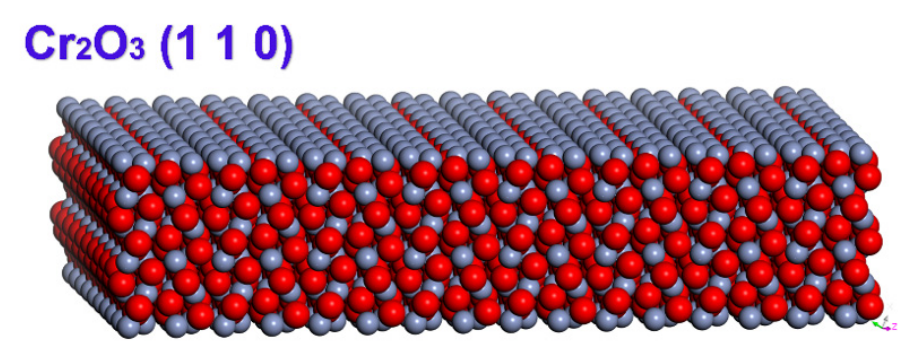

\section{$\mathrm{Cr}_{2} \mathrm{O}_{3}\left(\begin{array}{lll}2 & 0 & 0\end{array}\right)$}

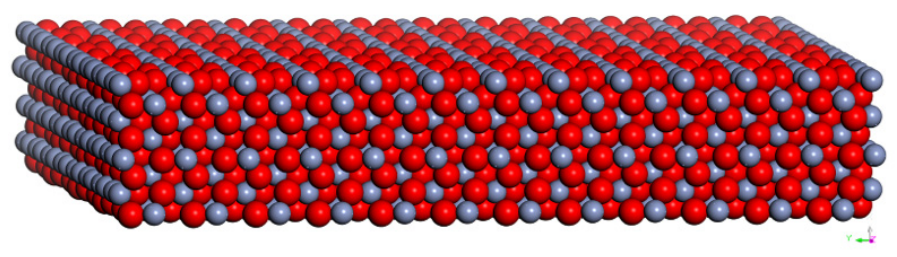

\section{$\mathrm{Cr}_{2} \mathrm{O}_{3}(2 \mathrm{1} 1)$}

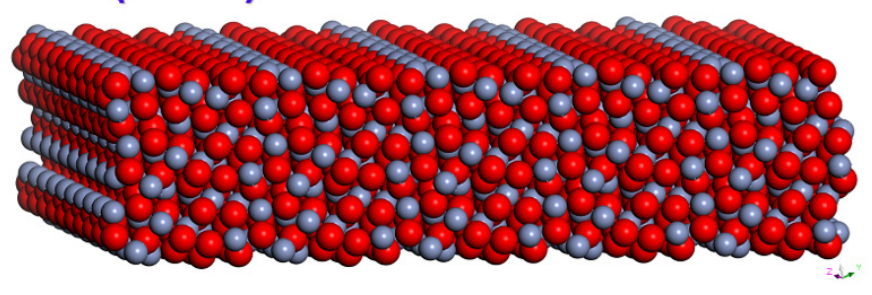

Figure 5. $\mathrm{Cr}_{2} \mathrm{O}_{3}$ surface model diagram (red is $\mathrm{O}$ atom, gray is $\mathrm{Cr}$ atom). 


\subsubsection{MD and QM Simulation}

Before calculating the model, it is necessary to optimize the structure of the PET molecular model to obtain the equilibrium structure of the PET molecular model, and use the first-principle electronic structure calculation of quantum mechanics to geometrically optimize the PET molecular structure. The simulation calculation is performed using the DMOL3 module in the Materials Studio 8.0 software, and the Perdew-Burke-Ernzerhof (PBE) functional in the generalized gradient approximation (GGA) proposed by Perdew is used to describe the exchange-correlation interaction between electrons [41]. The convergence accuracy is $1.0 \times 10^{-5} \mathrm{eV} / \mathrm{atom}$, the maximum force convergence accuracy acting on a single atom is $0.002 \mathrm{eV} / \AA$, the maximum pressure convergence accuracy is $0.1 \mathrm{GPa}$, and the maximum displacement convergence accuracy is $0.005 \AA$. The self-consistent accuracy of self-consistent filed $(\mathrm{SCF})$ is set as the single atom energy converges to $1.0 \times 10^{-6} \mathrm{eV}$, and the grid size of the k-point in the Brillouin zone is $1 \times 1 \times 1$.

We optimized the structure of the model system containing PET molecules and oxide surfaces, and obtain a balanced structure model with minimized energy. The model was subjected to 200ps MD simulation, and the simulation was performed under the condition of 500K temperature of the NVT system to obtain a balanced structure. Using the COMPASS force field in atomic simulation to simulate the interaction between PET molecules and chromium oxide molecules [42,43], Ghasem Bahlakeh [44] used the same method to study the interaction between epoxy resin and iron oxide molecular systems. Ewald- and atom-based methods were used to calculate the electrostatic interaction force and van der Waals force. The MD simulation used the Anderson monitor to monitor the temperature, and used the velocity calculus method to solve the Newtonian equation of motion, with an integration step of $1 \mathrm{ps}$. In the simulation process, all atoms in the oxide system are constrained, and the PET molecules do not impose constraints on the MD simulation.

\subsubsection{Interaction Energy Calculation}

In order to quantitatively study the interaction mechanism between the micro-interfaces of the coated iron and comprehensively evaluate the binding ability between the surface molecules of chromium oxide and the PET molecular chains on a micro-scale, the binding energies between the PET material and the three crystal plane structure models were calculated. Using the equilibrium structure model obtained at the end of the MD simulation, the interface interaction energy between the PET molecular system and the chromium oxide surface model with three different crystal surface structures is calculated according to the following formula [42-44]:

$$
E=E_{\text {total }}-\left(E_{\text {surface }}+E_{P E T}\right)
$$

In the formula: E represents the binding energy between the PET molecular system and the oxide model; $E_{\text {total }}$ represents the total energy of the equilibrium structure after the MD simulation calculation; $E_{\text {surface }}$ represents the energy of the oxide surface; and $E_{P E T}$ represents the energy of the PET molecule.

When calculating the total energy of the equilibrium structure after the MD simulation, we canceled all fixed atoms in the model to obtain an accurate total energy of the flat energy structure, and also canceled the constraints of all atoms during calculation.

\section{Results and Discussion}

\subsection{Analysis of the Experimental Results}

The microstructure of tin free steel (TFS) was evaluated by SEM analyses, as shown in Figure 6. By comparing the microscopic images of the blank steel plate and the chrome plate under different magnification conditions, it can be clearly seen that there are obvious grinding streaks on the surface of the blank steel plate, while the grinding streaks on the surface of the chrome steel plate are relatively 
inconspicuous. This is because the presence of the chromium-plated layer on the surface of the chrome-plated steel sheet weakens the microscopic morphology of the surface of the blank steel sheet.

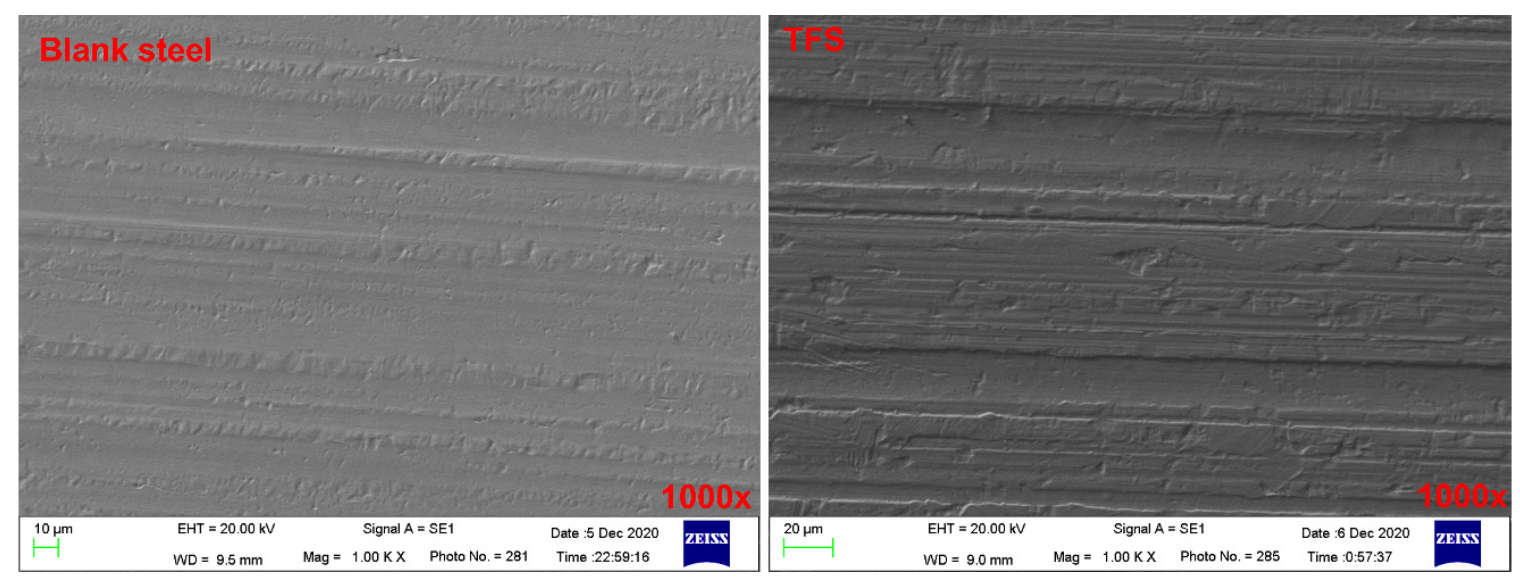

Figure 6. The SEM images of blank steel and TFS.

Figure 7 shows the SEM image of blank steel and TFS samples under 3000 times. We randomly selected a test line in the image for EDS scanning. It was found that the $\mathrm{Cr}$ element on the surface of the TFS is significantly higher than other elements such as $\mathrm{Mn}, \mathrm{Si}, \mathrm{C}$, and $\mathrm{Ni}$, while the content of the $\mathrm{Cr}$ element on the blank steel surface is very close to other elements. This shows that the chromium layer on the TFS surface completely covers the blank steel surface. It further illustrates that the bonding between the PCS interface occurs between the plating layer and the PET.
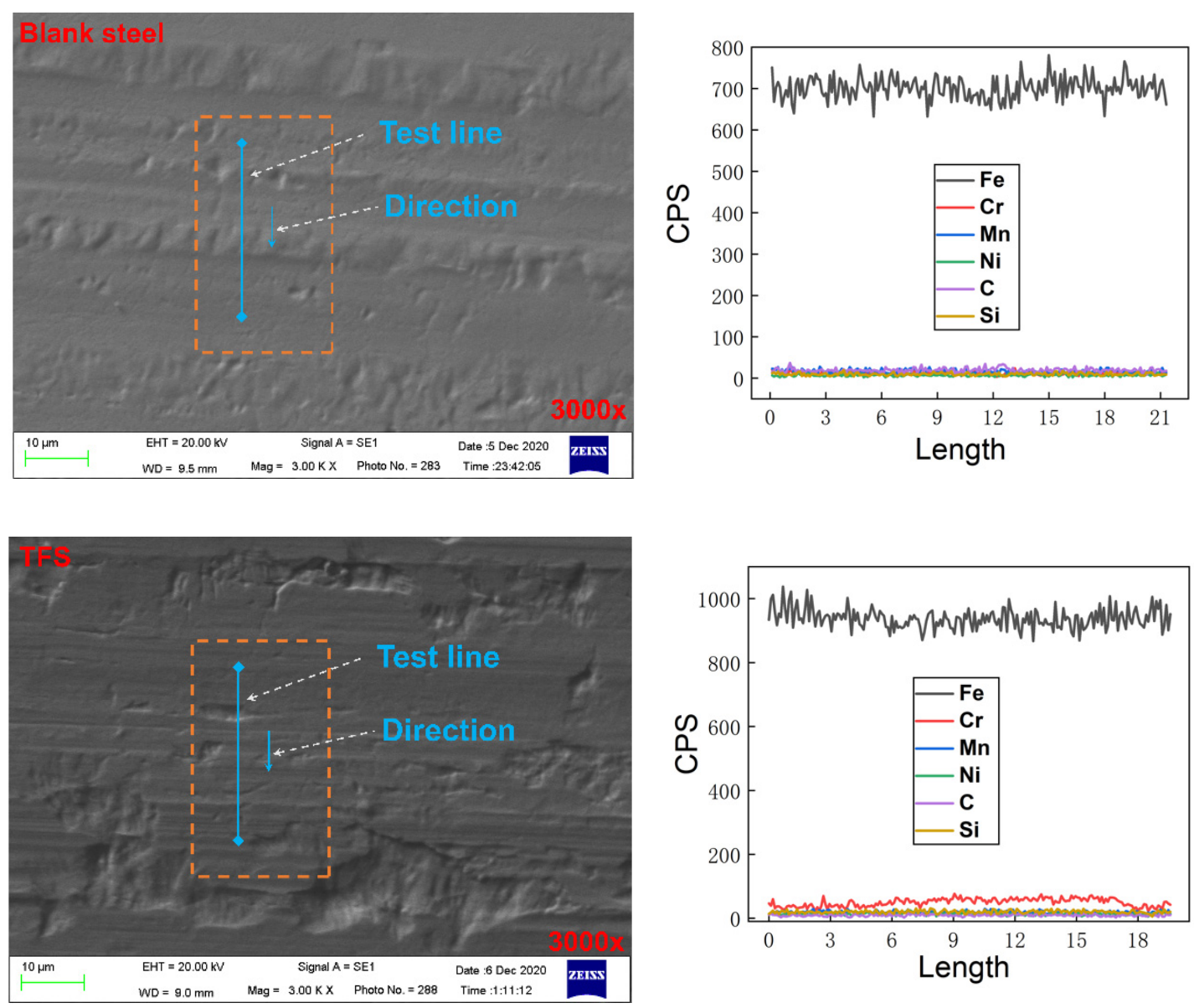

Figure 7. The SEM images and EDS curve of the blank steel and TFS. 
The chemical composition of chromium coating on the TFS surface was analyzed by XPS. It can be seen from Figure 8 that there are signal peaks of $\mathrm{Cr} 2 \mathrm{p}, \mathrm{O} 1 \mathrm{~s}, \mathrm{Si} 2 \mathrm{p}$, and C1s on the surface of the TFS. Among them, the $\mathrm{C}$ element is the result of introducing contaminant elements in the sample analysis process, and there is no $\mathrm{C}$ element on the surface of the coating. Part of the $\mathrm{O}$ element must come from the oxide or hydroxide formed by $\mathrm{Cr}$ and $\mathrm{O}$, but from the content of the surface elements in Table 1 , the content of oxygen is much greater than that of pure $\mathrm{Cr}$ oxide. It is likely that part of it comes from bound water molecules. The $\mathrm{Si}$ element comes from additives in the $\mathrm{Cr}$ plating process.

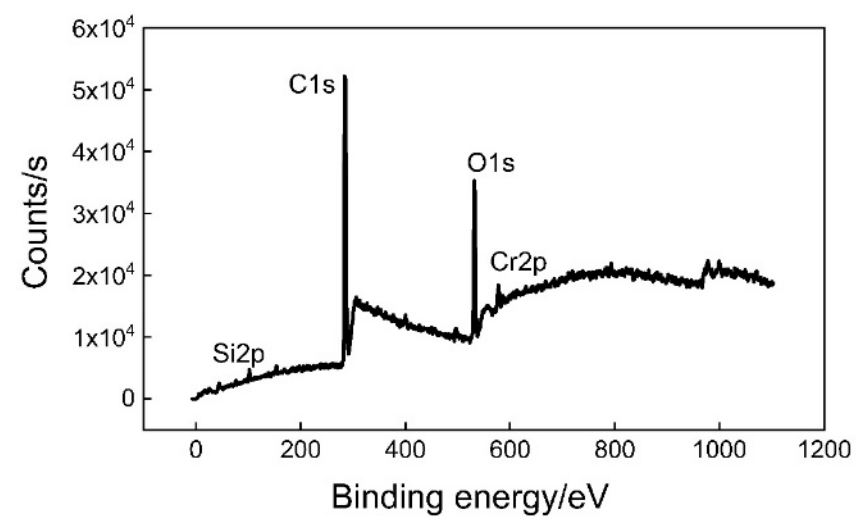

Figure 8. XPS spectra of the TFS surface.

Table 1. The element content of the TFS surface.

\begin{tabular}{ccc}
\hline Name & Peak BE & Atomic \% \\
\hline Cr2p & 577.07 & 0.76 \\
C1s & 284.82 & 83.52 \\
O1s & 532.09 & 13.72 \\
\hline
\end{tabular}

Figure 9 shows the spectrum of Cr on the TFS surface. It can be seen that the chemical shift of the $\mathrm{Cr}$ moves towards higher binding energy. This indicates that chromium compounds exist on the surface of TFS. Both Cr2p1/2 and Cr2p2/3 have broad peaks, indicating that chromium may have multiple valence states or molecular structures.

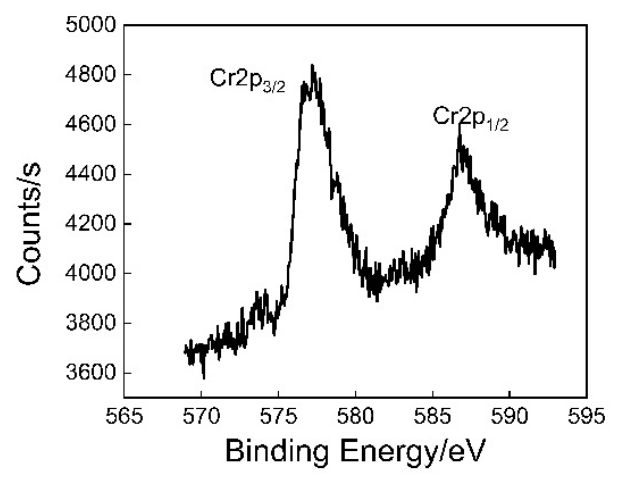

Figure 9. The XPS spectra of $\mathrm{Cr}$ in the TFS.

We used XPSPEAK software to fit the peaks of Cr2p3/2 and Cr2p1/2, as shown in Figure 10. Cr2p3/2 fits three sub-peaks, a, b, and c, and the corresponding binding energies are 577.4, 576.5, and $578.5 \mathrm{eV}$, respectively. We found the binding energy data in national institute of standards and technology (NIST), and the corresponding binding energy compounds are $\mathrm{Cr}(\mathrm{OH})_{3}, \mathrm{Cr}_{2} \mathrm{O}_{3}$, and $\mathrm{CrO}_{3}$. $\mathrm{Cr} 2 \mathrm{p} 1 / 2$ fit two sub-peaks, $\mathrm{d}$ and e, and the corresponding binding energies are 586.4 and $586.8 \mathrm{eV}$, respectively. We found the binding energy data in NIST. The corresponding binding energy compounds 
are $\mathrm{Cr}_{2} \mathrm{O}_{3}$ and $\mathrm{Cr}(\mathrm{OH})_{3}$. Combined with the fitting results of $\mathrm{Cr} 2 \mathrm{p} 3 / 2$ and $\mathrm{Cr} 2 \mathrm{p} 1 / 2$, the chemicals of the surface coating of TFS are mainly $\mathrm{Cr}(\mathrm{OH})_{3}, \mathrm{Cr}_{2} \mathrm{O}_{3}$, and $\mathrm{CrO}_{3}$, as shown in Table 2. The TFS is prepared by electroplating the hydrated chromium oxide layer on the surface of blank steel by the method of cathodic plating. The electrolyte used is a $\mathrm{CrO}_{3}$ solution, so the $\mathrm{CrO}_{3}$ in the coating should be the residue of the electrolyte on the surface of the steel sheet. $\mathrm{Cr}(\mathrm{OH})_{3}$ and $\mathrm{Cr}_{2} \mathrm{O}_{3}$, are the products generated during the electroplating process.

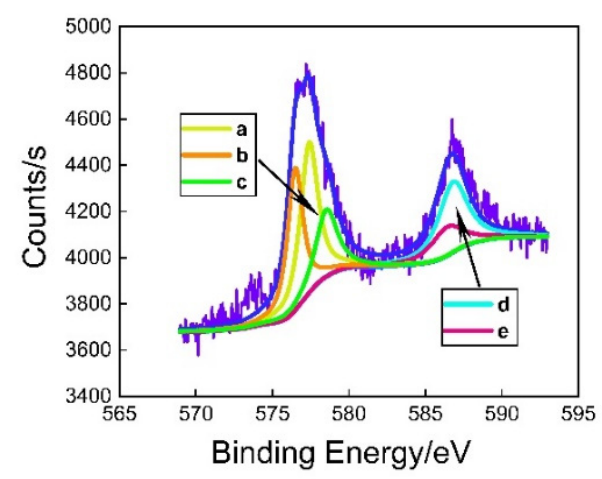

Figure 10. The fitting curve of the Cr XPS in the TFS.

Table 2. The curve fitted by XPSPEAK corresponds to the compound in NIST.

\begin{tabular}{cccc}
\hline Name & Number & Binding Energies/eV & Compounds \\
\hline $\mathrm{Cr} 2 \mathrm{p} 3 / 2$ & $\mathrm{~b}$ & 577.4 & $\mathrm{Cr}(\mathrm{OH})_{3}$ \\
$\mathrm{Cr} 2 \mathrm{p} 3 / 2$ & $\mathrm{a}$ & 576.5 & $\mathrm{Cr}_{2} \mathrm{O}_{3}$ \\
$\mathrm{Cr} 2 \mathrm{p} 3 / 2$ & $\mathrm{c}$ & 578.5 & $\mathrm{CrO}_{3}$ \\
$\mathrm{Cr} 2 \mathrm{p} 1 / 2$ & $\mathrm{e}$ & 586.4 & $\mathrm{Cr}_{2} \mathrm{O}_{3}$ \\
$\mathrm{Cr} 2 \mathrm{p} 1 / 2$ & $\mathrm{~d}$ & 586.8 & $\mathrm{Cr}(\mathrm{OH})_{3}$ \\
\hline
\end{tabular}

Since the coating process of PCS is a roll composite at high temperature, $\mathrm{Cr}(\mathrm{OH})_{3}$ and $\mathrm{Cr}_{2} \mathrm{O}_{3}$ can react to produce $\mathrm{Cr}_{2} \mathrm{O}_{3}$ at a high temperature. Therefore, the uppermost compound on the TFS surface during coating is $\mathrm{Cr}_{2} \mathrm{O}_{3}$ and bound water molecules.

\subsection{Interface Bonding Mechanism}

\subsubsection{MD and QM Simulation Results}

The MD simulation calculation was carried out using the modeling method described in Section 2.3.2. Figure 11 indicates the initial input cells and the corresponding final configurations obtained at the end of 200 ps MD simulations for PET molecules on the $\mathrm{Cr}_{2} \mathrm{O}_{3}$ (110) (a, a') surface, $\mathrm{Cr}_{2} \mathrm{O}_{3}(200)\left(b, b^{\prime}\right)$ surface, and $\mathrm{Cr}_{2} \mathrm{O}_{3}(211)$ (c, c') surface. Comparing Figures 11a and 11a', it can be found that after a certain period of MD simulation, the distance between the PET molecule and the highest atomic layer on the $\mathrm{Cr}_{2} \mathrm{O}_{3}$ (110) surface is greatly reduced, and the PET molecules move to the surface of $\mathrm{Cr}_{2} \mathrm{O}_{3}$ (110). This indicates that the PET molecules have compounded with the $\mathrm{Cr}_{2} \mathrm{O}_{3}$ (110) surface. Observing the final structure after MD simulation, it is found that the oxygen atom in the PET molecule $\mathrm{C}=\mathrm{O}$ bond is the closest to the highest atomic layer on the $\mathrm{Cr}_{2} \mathrm{O}_{3}$ (110) surface, similar to the oxygen atom in the PET molecule $\mathrm{C}=\mathrm{O}$ bond pulling the entire PET molecules to the surface of chromium oxide, which is caused by the Lewis acid-base interaction between the electrons in the $\mathrm{O}$ atoms and the surface of positively charged $\mathrm{Cr}$ ions. $\mathrm{O}$ atoms act as electron donors to provide electrons to the surface of the chromium oxide and are positively charged. The $\mathrm{Cr}$ ions on the metal surface accept electrons as electron acceptors to make $\mathrm{O}$ atoms move to the surface of the chromium oxide, which explains the micro-interface recombination mechanism of coated iron, that is, the coated iron is formed through the oxygen atom in the $\mathrm{C}=\mathrm{O}$ bond of the PET molecule and $\mathrm{Cr}_{2} \mathrm{O}_{3}$ (110). The compound was formed by the Lewis acid-base interaction between the $\mathrm{Cr}$ atoms on the surface. 

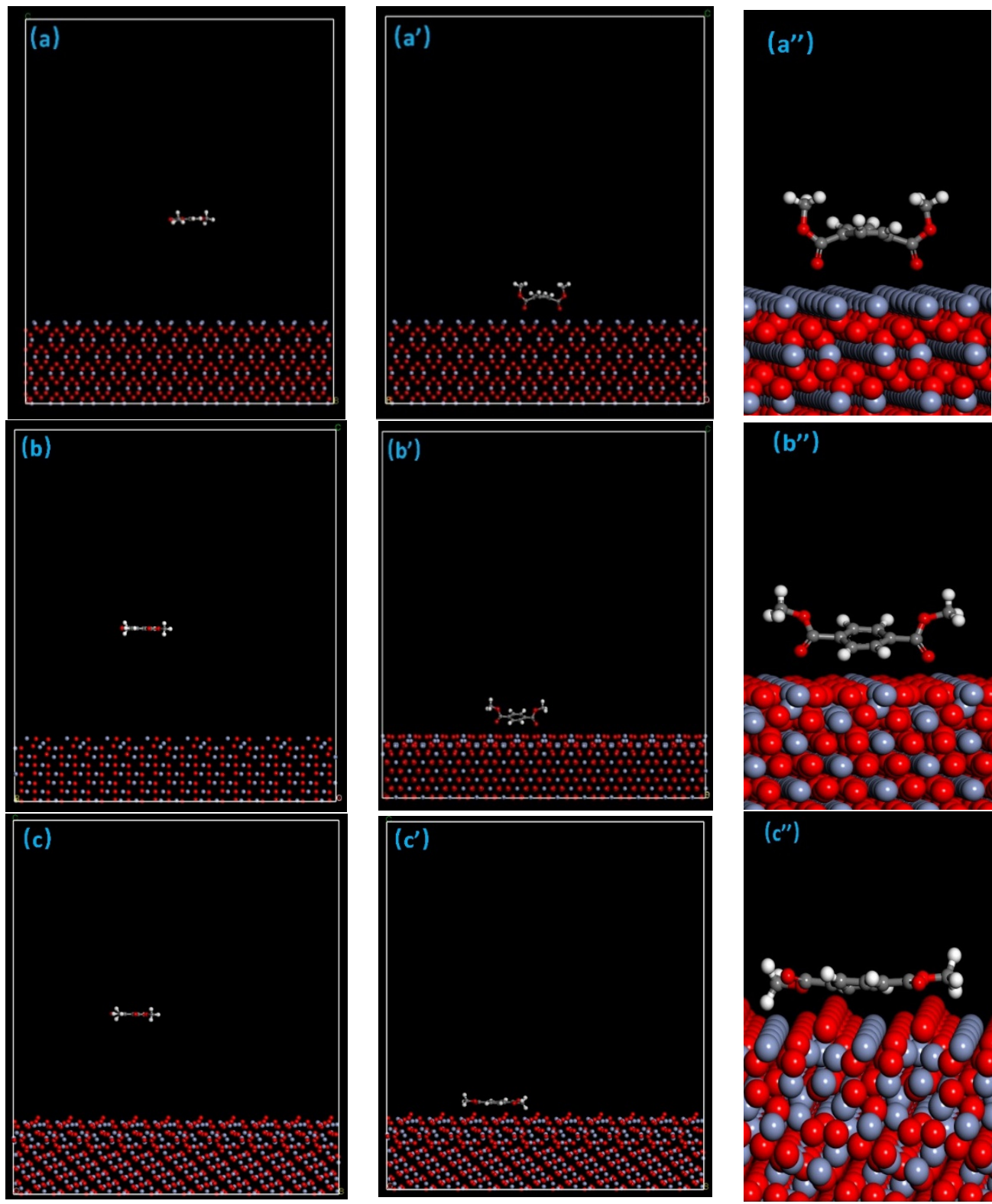

Figure 11. The initial and final configurations of the $\mathrm{Cr}_{2} \mathrm{O}_{3}(110)\left(\mathbf{a}, \mathbf{a}^{\prime}, \mathbf{a}^{\prime \prime}\right)$ surface, $\mathrm{Cr}_{2} \mathrm{O}_{3}(200)\left(\mathbf{b}, \mathbf{b}^{\prime}, \mathbf{b}^{\prime \prime}\right)$ surface and $\mathrm{Cr}_{2} \mathrm{O}_{3}(211)\left(\mathbf{c}, \mathbf{c}^{\prime}, \mathbf{c}^{\prime \prime}\right)$ surface interacting with PET molecules (white is $\mathrm{H}$ atom, red is $\mathrm{O}$ atom, gray is $\mathrm{C}$ atom).

Figure $11 b, b^{\prime}, b^{\prime \prime}$ and Figure $11 c, c^{\prime}, c^{\prime \prime}$ are the initial structure models of $\mathrm{PET}^{2}$ and $\mathrm{Cr}_{2} \mathrm{O}_{3}(200)$, and the $\mathrm{Cr}_{2} \mathrm{O}_{3}(211)$ plane and the final structure model after 200ps MD simulation. Combining Figure $11 \mathrm{a}, \mathrm{a}^{\prime}, \mathrm{a}^{\prime \prime}$, by comparing the initial structure and final structure of the three groups of models, it can be found that the PET molecules in the three groups of models have all moved to the surface of the chromium oxide, and the same final result is obtained after a longer MD simulation. In the structural model, the positioning of PET molecules near the surface of the chromium oxide proves that the PET molecules are compounded with the surface of the chromium oxide. Comparing Figure $11 b^{\prime}, c^{\prime}$, it can be found that the PET molecular shapes in the final structural models of the two crystal planes are relatively similar, which is different from that in Figure 11a', where the oxygen atoms in PET are the closest to the highest atomic layer of chromium oxide.

Figure $11 b^{\prime}, c^{\prime}$ show that the $\mathrm{H}$ atom in the benzene ring is the closest to the highest atomic layer of chromium oxide, while the $\mathrm{O}$ in $\mathrm{C}=\mathrm{O}$ is next to the highest atomic layer of chromium oxide. This is caused by the different structure of the chromium oxide surface, $\mathrm{Cr}_{2} \mathrm{O}_{3}(110)$. The highest layer atoms 
on the surface are all $\mathrm{Cr}$ atoms, while the highest layer atoms on the $\mathrm{Cr}_{2} \mathrm{O}_{3}(200)$ surface are both $\mathrm{Cr}$ atoms and $\mathrm{O}$ atoms, coexisting. Although all the highest layer atoms on the $\mathrm{Cr}_{2} \mathrm{O}_{3}$ (211) surface are all $\mathrm{Cr}$ atoms, the distance between the $\mathrm{Cr}$ atoms in each row is wide. The $\mathrm{O}$ atoms under the chromium layer are not completely covered by chromium atoms. From Figure $11 b^{\prime}, c^{\prime}$, can be seen that the $\mathrm{H}$ atom on the benzene ring in the PET molecule and the $\mathrm{O}$ on the surface of the chromium oxide are combined by forming a hydrogen bond, and the $\mathrm{O}$ in the $\mathrm{C}=\mathrm{O}$ bond also occurs simultaneously with the surface $\mathrm{Cr}$ atom acid-base interaction.

\subsubsection{Interaction Energy Calculation}

According to the binding energy calculation formula in Section 2.3.3, the binding energy between the three model PET molecules and the chromium oxide surface was calculated. Before calculation, all atoms in the model were unconstrained. The calculation results are shown in Figure 12 and Table 3.

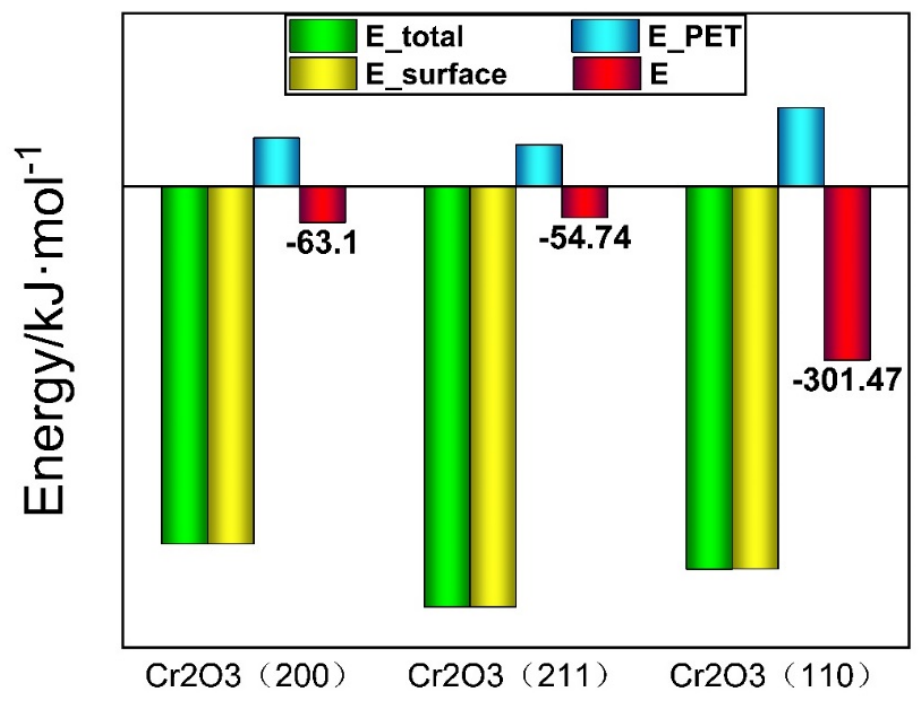

Figure 12. The binding energy of the $\mathrm{Cr}_{2} \mathrm{O}_{3}$ surface with PET.

Table 3. The element content of the TFS surface.

\begin{tabular}{lcccc}
\hline & $E_{\text {total }}(\mathbf{k J} / \mathbf{m o l})$ & $E_{\text {surface }}(\mathbf{k J} / \mathbf{m o l})$ & $E_{P E T}(\mathbf{k J} / \mathbf{m o l})$ & $\mathbf{E ~ ( k J / m o l )}$ \\
\hline $\mathrm{Cr}_{2} \mathrm{O}_{3}(200)$ & -620596.21 & -620616.96 & 83.86 & -63.10 \\
$\mathrm{Cr}_{2} \mathrm{O}_{3}(211)$ & -729577.13 & -729594.39 & 72.00 & -54.74 \\
$\mathrm{Cr}_{2} \mathrm{O}_{3}(110)$ & -663991.26 & -663826.00 & 136.21 & -301.47 \\
\hline
\end{tabular}

It can be seen from Table 3 that the binding energies between the surface of the $\mathrm{Cr}_{2} \mathrm{O}_{3}$ (110), (200), (211) and PET molecules are $-301.47,-63.10$, and $-54.74 \mathrm{~kJ} / \mathrm{mol}$, respectively. Previous studies have shown that when the binding energy is $-14.28 \mathrm{~kJ} / \mathrm{mol}<\mathrm{E}<0 \mathrm{~kJ} / \mathrm{mol}$, it is physical adsorption; when the binding energy $\mathrm{E}<-14.28 \mathrm{~kJ} / \mathrm{mol}$, it is chemical adsorption. It can be seen that the composite type between the chromium oxide surface and the PET molecule is chemical adsorption, which further proves that the PET molecule and the chromium oxide surface are composited, and the binding energy between the three crystal plane structures of chromium oxide and the PET molecule is $\mathrm{Cr}_{2} \mathrm{O}_{3}(110)>$ $\mathrm{Cr}_{2} \mathrm{O}_{3}(200)>\mathrm{Cr}_{2} \mathrm{O}_{3}(211)$.

\subsubsection{Radial Element Concentration Distribution}

In order to further quantitatively analyze the mechanism of the combination of PET molecules and the surface of chromium oxide, the element radial concentration distributions of oxygen atoms and hydrogen atoms in the initial and final structures of the three models were calculated. Figure 12 
shows the concentration distribution of oxygen atoms and hydrogen atoms in the initial and final structures of different crystal plane models along the direction perpendicular to the surface.

It can be seen from Figure 13 that the distance between the oxygen atoms and hydrogen atoms in the initial structure of the three models relative to the highest layer of the chromium oxide surface is approximately $30 \AA$, and the distance between the oxygen atoms and carbon atoms in the final structure relative to the chromium oxide surface approximately $15 \AA$. It is further confirmed that the PET molecules have been composited with the surface of chromium oxide, and can be composited with the surface of chromium oxide with different crystal plane structures.
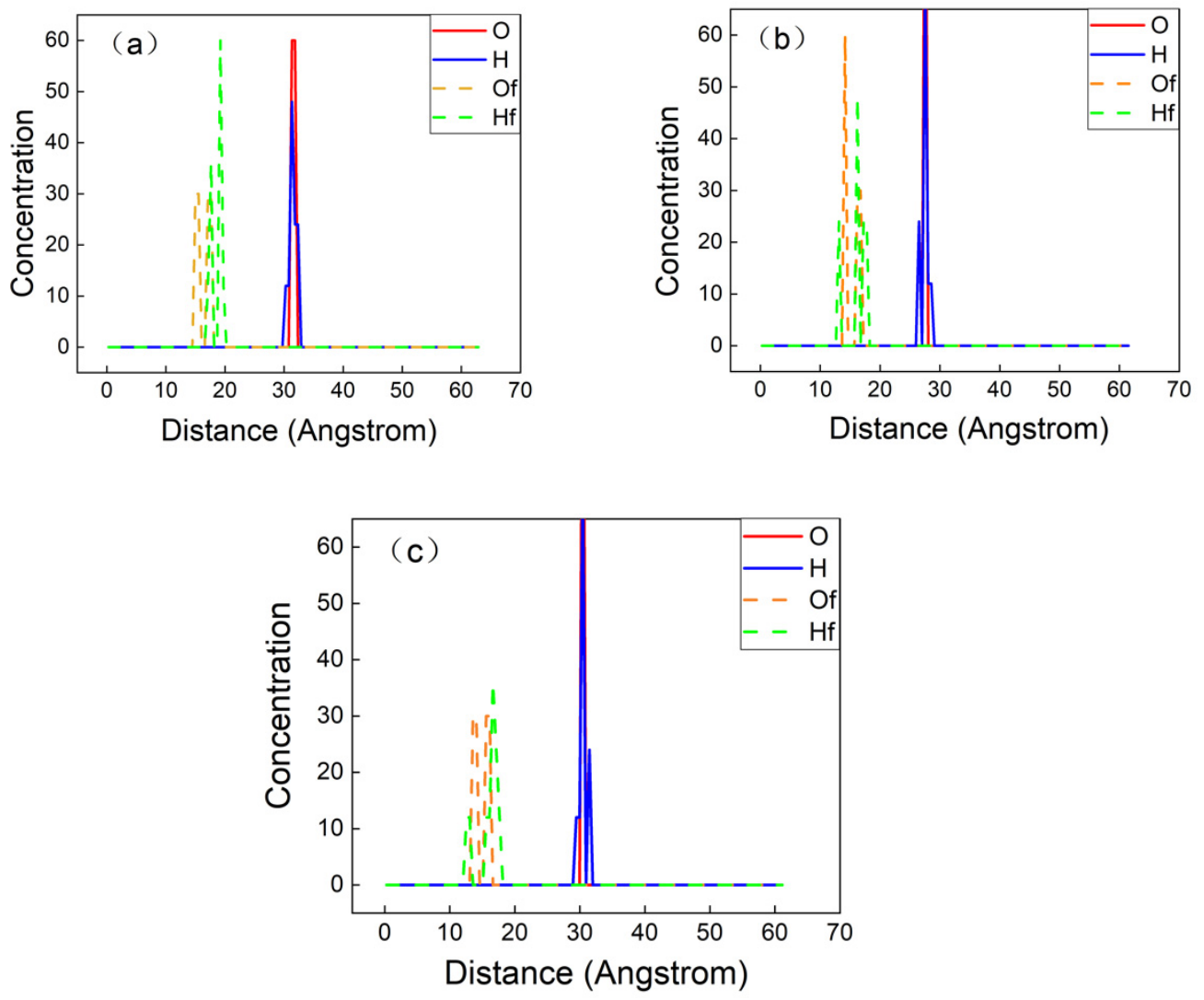

Figure 13. Concentration profiles of oxygen $(\mathrm{O})$ and hydrogen $(\mathrm{H})$ atoms in PET on top of $(\mathbf{a}) \mathrm{Cr}_{2} \mathrm{O}_{3}(110)$, (b) $\mathrm{Cr}_{2} \mathrm{O}_{3}$ (200), and (c) $\mathrm{Cr}_{2} \mathrm{O}_{3}$ (211) surfaces before (O and $\mathrm{H}$ ) and after (Of and Hf) MD simulations.

The frontier molecular orbital theory (FMO) was used to further reveal the bonding mechanism between the PET film and the chromium oxide layer proposed by Zumelzu [20] through acid-base interaction. Figure 14 shows the global minimum energy structure of PET molecules, the respective distributions of the highest occupied molecular orbital (HOMO), and the lowest occupied molecular orbital (LUMO). HOMO orbitals are related to the active sites that have the greatest ability to interact with metal atoms and provide electrons to the empty electron orbitals on the surface of metal atoms. The LUMO orbital of the PET film represents the active site that accepts electrons from the filled orbital of atoms on the metal surface.

It can be seen that the HOMO orbitals of the PET molecules are mainly oxygen atoms. The LUMO orbital is mainly a benzene ring and the carbon atom is connected to the benzene ring. The PET molecules donate delocalized electrons near the oxygen atoms to the low-energy unoccupied orbitals of the chromium atoms on the surface of the chromium oxide. PET molecules provide electrons, and the surface of the chromium oxide absorbs electrons, and recombines through acid-base interactions. 


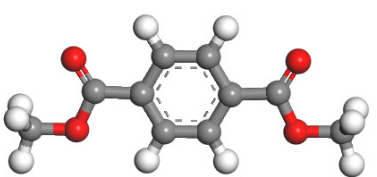

(1) Optimized molecular structure

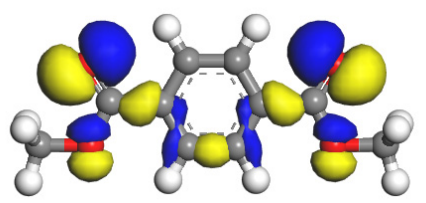

(2) $\mathrm{HOMO}$

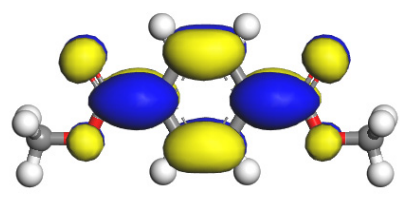

(3) LUMO

Figure 14. GGA/PW91-optimized structure and highest occupied molecular orbitals (HOMOs) and lowest occupied molecular orbital (LUMOs) of PET molecules.

Figure 15 shows the charge of the oxygen atoms in the PET molecule. The charge of the oxygen atom in the $\mathrm{C}=\mathrm{O}$ bond is -0.450 , which is the highest electronegativity in the entire PET molecule. Therefore, the combination of the PET molecule and the chromium oxide molecule is mainly based on the $\mathrm{O}$ atom in the $\mathrm{C}=\mathrm{O}$ bond. The final stable structure model of the three crystal planes in Figure 9 further illustrates that the oxygen atoms in the PET molecule and the chromium atoms on the chromium oxide surface are compounded through acid-base interactions.

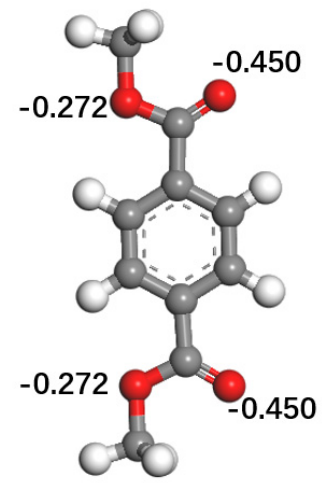

Figure 15. Partial atomic charge of PET molecules.

\subsection{Chromium Oxide Surface with Different Hydroxyl Content}

The XRD experiment results show that there are a large number of hydrogen and oxygen atoms on the surface of TFS strip steel. Other literature about layers has pointed out through experiments and analysis of the binding energy of chromium oxide that there are a large number of hydroxyl groups on the surface of TFS steel plate (quoted from Wuxi steel plate). Since all the atoms on the top layer of the $\mathrm{Cr}_{2} \mathrm{O}_{3}$ (110) are $\mathrm{Cr}$ atoms, the $\mathrm{Cr}_{2} \mathrm{O}_{3}$ (200) surface with a slightly larger binding energy is used as the base material model for modeling. Using the method of adding hydrogen atoms to the surface of oxygen atoms to build a hydroxylated surface model, we established $25 \%, 50 \%, 75 \%$, and $100 \%$ hydroxyl concentration $\mathrm{Cr}_{2} \mathrm{O}_{3}$ (200) surface models, respectively. We placed the PET molecules in parallel at 50A above the $\mathrm{Cr}_{2} \mathrm{O}_{3}$ (200) surface with different hydroxyl concentrations to eliminate the effect of the position of the PET above the chromium oxide surface on the settlement result, as shown in Figure 16. The formation of hydrogen bonds adopts the definition method proposed by Ghasem. Ghasem defined two necessary conditions for the formation of hydrogen bonds when studying the interface bonding mechanism between different iron oxide types and epoxy resins: two hydrogen donor atoms (D) and hydrogen atoms (A) sharing one hydrogen atom $(\mathrm{H})$ form a hydrogen bond when the following geometric conditions are met, where (1) the distance $\mathrm{H} \cdot \mathrm{A}$ should be less than 2.5A; and (2) the angle D-H..A should be greater than $90^{\circ}$ [44]. 

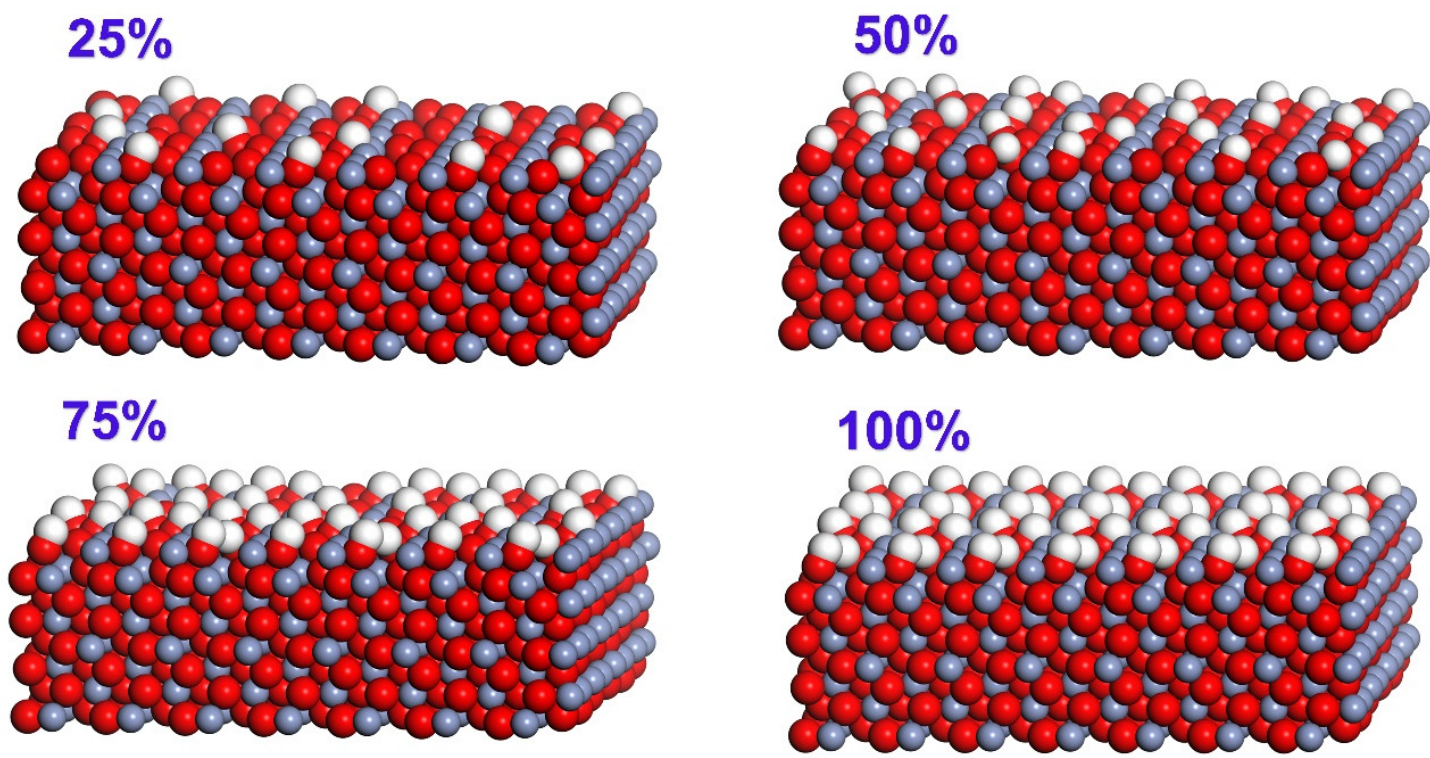

Figure 16. $\mathrm{Cr}_{2} \mathrm{O}_{3}$ (200) surface with different hydroxyl concentration (white is $\mathrm{H}$ atom, red is $\mathrm{O}$ atom, gray is $\mathrm{C}$ atom).

It can be seen from Figure 16 that the PET molecules in all models have moved to the surface. The oxygen atom in $\mathrm{C}=0$ in the PET molecule migrates to the surface of the chromium oxide with the entire PET molecule, and recombines with the hydroxyl group on the surface of the chromium oxide to form a hydrogen bond. The cyan dotted line in Figure 17 represents hydrogen bonding. Corresponding to $25 \%, 25 \%, 25 \%$, and $25 \%$, the number of hydrogen bonds generated by the hydroxyl concentration model are 2,3,3, and 4, respectively. With the increase of hydroxyl concentration on the surface of chromium oxide, the number of hydrogen bonds gradually increases.
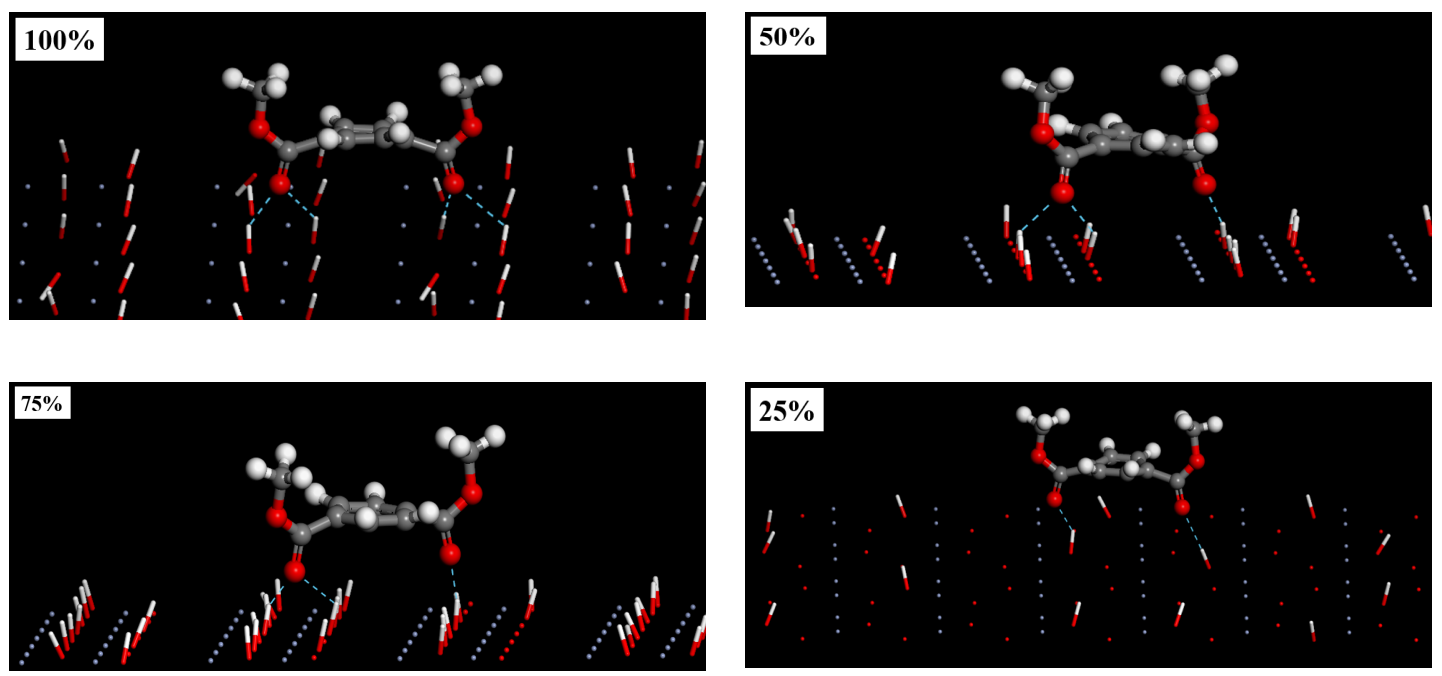

Figure 17. Side view of PET molecule complexation with $\mathrm{Cr}_{2} \mathrm{O}_{3}$ with different hydroxyl concentration (the cyan dotted line represents the hydrogen bond).

We calculated the binding energy of the model using the formula in Section 2.3.3. The binding energies corresponding to $25 \%, 25 \%, 25 \%$ and $25 \%$ hydroxyl concentration models are -223.4 , $-227.6,-231.7$, and $-237 \mathrm{KJ} / \mathrm{mol}$, respectively, as shown in Figure 18. With the increase of hydroxyl concentration on the surface of the chromium oxide, the binding energy between the PET and $\mathrm{Cr}_{2} \mathrm{O}_{3}$ (200) gradually increases, as shown in Figure 17. This is precisely due to the increase in the number of generated hydrogen bonds, which leads to the increase in binding energy. 


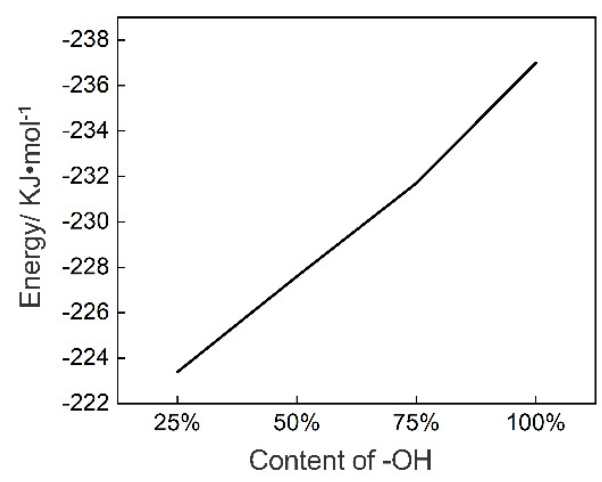

Figure 18. Different concentrations of hydroxyl groups.

\section{Conclusions}

The micro morphology of the coating on the surface of TFS was measured by SEM. The chrome-plated layer evenly covers the surface of the blank steel, and the presence of the chrome-plated layer weakens the grinding streaks on the surface of the blank steel. The chemical composition and full spectrum of the chromium plating layer on the surface of the TFS were obtained through XPS experiments. Using XPSPEAK software to fit the spectra, it is concluded that the composition of the chromium plating layer on the TFS surface is $\mathrm{Cr}(\mathrm{OH})_{3}, \mathrm{Cr}_{2} \mathrm{O}_{3}$, and $\mathrm{CrO}_{3}$.

The bonding mechanism of PCS micro-interface is explained by MD calculation combined with the first principles method. The chromium oxide surface and PET molecular models at the micro-scale were established respectively, and MD and QM simulations under certain parameter conditions were carried out.

The composite models of the $\mathrm{Cr}_{2} \mathrm{O}_{3}(110), \mathrm{Cr}_{2} \mathrm{O}_{3}(200)$, and $\mathrm{Cr}_{2} \mathrm{O}_{3}$ (211) surfaces and PET molecules were established respectively. It is pointed out that PET molecules and chromium oxide molecules are compounded in the form of acid-base interactions. The carbonyl oxygen (electron pair donor $=$ base) shares its electrons with chromium (electron pair acceptor $=$ acid). We verified and proved the acid-base interaction theory proposed by Zumlzu [20]. The binding energy between $\mathrm{Cr}_{2} \mathrm{O}_{3}$ (110), $\mathrm{Cr}_{2} \mathrm{O}_{3}$ (200), $\mathrm{Cr}_{2} \mathrm{O}_{3}(211)$, and the PET molecules is $-301.47 \mathrm{KJ} / \mathrm{mol},-63.10 \mathrm{KJ} / \mathrm{mol}$, and $-54.74 \mathrm{KJ} / \mathrm{mol}$. The binding energy between $\mathrm{Cr}_{2} \mathrm{O}_{3}$ (110) and the PET molecules is the largest.

A surface model of $\mathrm{Cr}_{2} \mathrm{O}_{3}$ (200) with different hydroxyl concentrations was established. Through MD and QM calculations, radial element concentration analysis, and frontier orbital theory, it is proved that the PET and hydroxylated chromium oxide surface are compounded in the form of hydrogen bonds. The oxygen atom in the $\mathrm{C}=\mathrm{O}$ bond in the PET molecule combines with the hydroxyl group on the surface of $\mathrm{Cr}_{2} \mathrm{O}_{3}$ to form a hydrogen bond, which verifies the hydrogen bond recombination theory proposed by Tanaka [18]. It is calculated that the binding energies of the composite model with $25 \%, 50 \%, 75 \%$, and $100 \%$ hydroxyl concentration are $-223.4,-227.6,-231.7$, and $-237 \mathrm{KJ} / \mathrm{mol}$, respectively. The increase in the concentration of hydroxyl on the surface of the chromium oxide helps to improve the interfacial binding energy. The key to improve the binding energy of the PCS interface is to increase the concentration of hydroxyl groups on the surface of TFS. Increasing the hydroxyl content in the hydrated chromium oxide layer on the surface of TFS is an effective way to improve the bonding strength of PCS.

Author Contributions: Conceptualization, J.L.; Data curation, J.L. and B.Z.; Formal analysis, B.Z.; Funding acquisition, Q.Z.; Investigation, J.L.; Methodology, Q.Z.; Project administration, B.Z.; Software, J.L.; Validation, B.Z. and M.Y.; Visualization, M.Y.; Writing—original draft, J.L.; Writing—review \& editing, J.L. and Q.Z. All authors have read and agreed to the published version of the manuscript.

Funding: This research was funded by National Natural Science Foundation of China (No. U1760106).

Conflicts of Interest: The authors declare no conflict of interest. 


\section{References}

1. Zhang, Q.; Liu, J.; Zhang, B.; Zhang, L. Advances in Theory and Technology for Laminating of Polymer-coated Steel. J. Mech. Eng. 2019, 8, 30-45. [CrossRef]

2. Morita, S.I.; Iwashita, H.; Tanaka, A. Effect of Contact Cooling Length between the Laminating Rolls on the Biaxial Orientation Changes of Polyester Film in the Laminating Process. J. Surf. Finish. Soc. Jpn. 2001, 52, 517-521. [CrossRef]

3. Takeshi, S.; Hiroki, I.; Masaaki, Y. The Mechanism of Wet Adhesion of the PET-laminated Steel Sheet. Tetsu-to-Hagane 2003, 89, 142-148.

4. Cho, C.K.; Kim, J.D.; Cho, K.; Park, C.E.; Lee, S.W.; Ree, M. Effects of the lamination temperature on the properties of poly (ethylene terephthalate-co-isophthalate) in polyester-laminated tin-free steel can-I. Characterization of poly (ethylene terephthalate-co-isophthalate). J. Adhes. Sci. Technol. 2000, 14, 1131-1143. [CrossRef]

5. Cho, C.K.; Kim, J.D.; Cho, K.; Park, C.E.; Lee, S.W.; Ree, M. Effects of the lamination temperature on the properties of poly (ethylene terephthalate-co-isophthalate) in polyester-laminated tin-free steel can-II. Adhesion mechanism of poly (ethylene terephthalate-co-isophthalate) to TFS. J. Adhes. Sci. Technol. 2000, 14, 1145-1157. [CrossRef]

6. Ruokolainen, R.B.; Sigler, D.R. The Effect of Adhesion and Tensile Properties on the Formability of Laminated Steels. J. Mater. Eng. Perform. 2008, 17, 330-339. [CrossRef]

7. Braasch, D.A.; Gillis, M.; Pramanik, M.; Ferguson, R.C. Detection of in Situ Early Corrosion on Polymer-Coated Metal Substrates. ACS Appl. Mater. Interfaces 2019, 11, 37193-37208. [CrossRef]

8. Iwashita, H.; Morita, S.I.; Tanaka, A. Development of Amorphous Layer of Biaxially Oriented Polyester Film on Laminated Steel in the Laminating Process. Tetsu-to-Hagane 2001, 87, 175-182. [CrossRef]

9. Terauchi, F.; Iwashita, H.; Tanaka, A.; Morita, S. Effect of Annealing Temperature on Adhesion of Polyester Film to Electrolytically Chromium Coated Steel. Tetsu-to-Hagane 1999, 85, 236-240. [CrossRef]

10. Matsubayashi, H. Metal Can using Polyester Film Laminated ECCS (Electrolytic chromium/chromium oxide-coated steel). Zairyo-to-Kankyo 2002, 51, 299-304. [CrossRef]

11. Lindner, M.; Rodler, N.; Jesdinszki, M.; Schmid, M.; Sängerlaub, S. Surface energy of corona treated PP, $\mathrm{PE}$ and PET films, its alteration as function of storage time and the effect of various corona dosages on their bond strength after lamination. J. Appl. Polym. Sci. 2018, 135, 45842. [CrossRef]

12. Liu, J.; Zhang, Q.; Geng, L.; Zhang, B.; Zhang, L. Study on evolution law of lateral thickness difference of Polymer-coated steel in laminating process. Mater. Today Proc. 2020, in press. [CrossRef]

13. Alexiou, V.F.; Mathioudakis, G.N.; Andrikopoulos, K.S.; Beobide, A.S.; Voyiatzis, G.A. Poly (ethylene Terephthalate) Carbon-Based Nanocomposites: A Crystallization and Molecular Orientation Study. Polymers 2020, 12, 2626. [CrossRef] [PubMed]

14. Anagri, A.; Baitukha, A.; Debiemme-Chouvy, C.; Lucas, I.T.; Pulpytel, J.; Mai Tran, T.T.; Tabibian, S.; Arefi-Khonsari, F. Nanocomposite coatings based on graphene and siloxane polymers deposited by atmospheric pressure plasma. Application to corrosion protection of steel. Surf. Coat. Technol. 2019, 377, 124928. [CrossRef]

15. Ubaid, F.; Radwan, A.B.; Naeem, N.; Shakoor, R.A.; Ahmad, Z.; Montemor, M.F.; Kahraman, R.; Abdullah, A.M.; Soliman, A. Multifunctional self-healing polymeric nanocomposite coatings for corrosion inhibition of steels. Surf. Coat. Technol. 2019, 372, 121-133. [CrossRef]

16. Bosh, N.; Deggelmann, L.; Blattert, C.; Mozaffari, H.; Müller, C. Synthesis and characterization of Halar polymer coating deposited on titanium substrate by electrophoretic deposition process. Surf. Coat. Technol. 2018, 347, 369-378.

17. Valega Mackenzie, F.O.; Thijsse, B.J. Study of Metal/Epoxy Interfaces between Epoxy Precursors and Metal Surfaces Using a Newly Developed Reactive Force Field for Alumina-Amine Adhesion. J. Phys. Chem. C 2015, 119, 4796-4804. [CrossRef]

18. Tanaka, A.; Hanafusa, T.; Kojyo, H.; Inui, T. Adhesion of biaxially oriented polyethylene terephthalate film to tin free steel. Trans. Iron Steel Inst. Jpn. 1987, 27, 638-644. [CrossRef]

19. Komai, M.; Taniguchi, A.; Shimizu, N.; Shimizu, K.; Tanaka, A. Effects of Composition and Microstructure of Hydrated Chromium Oxide on Adhesive Property of PET/I Film Laminated TFS. Tetsu-to-Hagane 1997, 83, 377-382. [CrossRef]

20. Zumelzu, E.; Rull, F.; Schmidt, P.; Boettcher, A.A. Structural analysis of polymer-metal laminates by electron microscopy and infrared spectroscopy. Surf. Coat. Int. Part B Coat. Trans. 2006, 89, 57-62. [CrossRef] 
21. Feng, L.; Yang, H.; Wang, F. Experimental and theoretical studies for corrosion inhibition of carbon steel by imidazoline derivative in $5 \% \mathrm{NaCl}$ saturated $\mathrm{Ca}(\mathrm{OH})_{2}$ solution. Electrochim. Acta 2011, 58, 427-436. [CrossRef]

22. Chen, S.; Yune, J.H.R.; Zhang, Z.Q.; Liu, Z.; Sridhar, N.; Wu, L.Y.L.; Chng, S.; Liu, J. Multiscale Modeling to Predict the Hydrophobicity of an Experimentally Designed Coating. J. Phys. Chem. C 2020, 124, 9866-9875. [CrossRef]

23. Poon, J.; Madden, D.C.; Wood, M.H. Surface Chemistry of Almandine Garnet. J. Phys. Chem. C 2020, 124, 5099-5117. [CrossRef]

24. Bhowmik, R.; Sihn, S.; Varshney, V.; Roy, A.K.; Vernon, J.P. Calculation of specific heat of polymers using molecular dynamics simulations. Polymers 2019, 167, 176-181. [CrossRef]

25. Cruz-Delgado, V.J.; Ávila-Orta, C.A.; Espinoza-Martinez, A.B.; Mata-Padilla, J.M.; Solis-Rosales, S.G.; Jalbout, A.F.; Medellín-Rodríguez, F.J.; Hsiao, B.S. Carbon nanotube surface-induced crystallization of polyethylene terephthalate (PET). Polymers 2014, 55, 642-650. [CrossRef]

26. Tinacba, E.J.C.; Isobe, M.; Karahashi, K.; Hamaguchi, S. Molecular dynamics simulation of $\mathrm{Si}$ and $\mathrm{SiO}_{2}$ reactive ion etching by fluorine-rich ion species. Surf. Coat. Technol. 2019, 380, 125032. [CrossRef]

27. Cui, W.; Huang, W.; Hu, B.; Xie, J.; Xiao, Z.; Cai, X.; Wu, K. Investigation of the Effects of Adsorbed Water on Adhesion Energy and Nanostructure of Asphalt and Aggregate Surfaces Based on Molecular Dynamics Simulation. Polymers 2020, 12, 2339. [CrossRef]

28. Buhl, K.B.; Agergaard, A.H.; Lillethorup, M.; Nikolajsen, J.P.; Pedersen, S.U.; Daasbjerg, K. Polymer Brush Coating and Adhesion Technology at Scale. Polymers 2020, 12, 1475. [CrossRef]

29. Yang, S.; Shin, H.; Cho, M. Molecular dynamics simulation and finite element analysis on mechanical behavior of oxygen functionalized graphene/polymer nanocomposites. J. Mech. Sci. Technol. 2019, 33, 307-314. [CrossRef]

30. Bahlakeh, G.; Ramezanzadeh, B.; Saeb, M.R.; Terryn, H.; Ghaffari, M. Corrosion protection properties and interfacial adhesion mechanism of an epoxy/polyamide coating applied on the steel surface decorated with cerium oxide nanofilm: Complementary experimental, molecular dynamics (MD) and first principle quantum mechanics (QM) simulation methods. Appl. Surf. Sci. 2017, 419, 650-669. [CrossRef]

31. Ta, T.D.; Tieu, A.K.; Zhu, H.; Kosasih, B. Adsorption of normal-alkanes on Fe(110), FeO(110), and Fe2O3(0001): Influence of iron oxide surfaces. J. Phys. Chem. C 2015, 119, 12999-13010. [CrossRef]

32. Zumelzu, E.; Cabezas, C.; Delgado, F. Performance and degradation analyses of traditional and ECCS canning tinplates in citric-citrate medium. J. Mater. Process. Technol. 2004, 152, 384-388. [CrossRef]

33. Morita, S.; Iwashita, H.; Tanaka, A.; Terauchi, F. Variations of biaxial orientation of polyester film on laminated steel in the laminating process. Tetsu-to-Hagane 2009, 86, 171-175. [CrossRef]

34. Liu, Z.; Zeng, K.; Zhao, Y. Polymer-Coated Steel: A green revolution in metal packaging for food and beverage. Packag. J. 2012, 4, 9-15.

35. Takeshi, S.; Hiroki, I.; Hideki, N.; Toyofumi, W. Development of "Universal brite type E" new film laminated TFS for 18L can and pail can. Mater. Jpn. 2005, 44, 145-147.

36. Zhang, H. Development and application of electrolytic chromium-coated steel (TFS) new products. South. Iron Steel 2002, 4, 13-16.

37. Zumelzu, E.; Rull, F.; Boettcher, A.A. Characterization and micro- and ultra-structural analysis of PET-based Co-rolled composite electrolytic chromium coated steel (ECCS). J. Mater. Process. Technol. 2006, 173, 34-39. [CrossRef]

38. Liang, H.; Xie, F.; Guo, F.; Chen, B.; Luo, F.; Jin, Z. Non-isothermal crystallization behavior of poly(ethyleneterephthalate)/poly (trimethylene terephthalate) blends. Polym. Bull. 2008, 60, 115-127. [CrossRef]

39. Kim, K.C.; Jang, S.S. Molecular dynamics simulation study on the structural properties of poly (ethyleneterephthalate) under uniaxial extension and thermal shrinkage processes. Curr. Appl. Phys. 2017, 18, 19-26.

40. Boronat, M.; Lopez-Ausens, T.; Corma, A. The acid-base and redox reactivity of $\mathrm{CeO}_{2}$ nanoparticles: Influence of the hubbard U term in DFT + U studies. Surf. Sci. 2016, 648, 212-219. [CrossRef]

41. Perdew, J.P.; Ruzsinszky, A.; Csonka, G.I.; Vydrov, O.A.; Scuseria, G.E.; Constantin, L.A.; Zhou, X.; Burke, K. Restoring the Density-Gradient Expansion for Exchange in a GGA for Solid and Surfaces. Phys. Rev. Lett. 2008, 100, 136406. [CrossRef] [PubMed] 
42. Semoto, T.; Tsuji, Y.; Yoshizawa, K. Molecular understanding of the adhesive force between a metal oxide surface and an epoxy resin. J. Phys. Chem. C 2011, 85, 11701-11708. [CrossRef]

43. Semoto, T.; Tsuji, Y.; Yoshizawa, K. Molecular understanding of the adhesive force between a metal oxide surface and an epoxy resin: Effects of surface water. Bull. Chem. Soc. Jpn. 2012, 85, 672-678.

44. Bahlakeh, G.; Ghaffari, M.; Saeb, M.R.; Ramezanzadeh, B.; De Proft, F.; Terryn, H. A Close-up of the effect of iron oxide type on the interfacial interaction between epoxy and carbon steel: Combined molecular dynamics simulations and quantum mechanics. Phys. Chem. 2016, 120, 11014-11026. [CrossRef]

Publisher's Note: MDPI stays neutral with regard to jurisdictional claims in published maps and institutional affiliations.

(C) 2020 by the authors. Licensee MDPI, Basel, Switzerland. This article is an open access article distributed under the terms and conditions of the Creative Commons Attribution (CC BY) license (http://creativecommons.org/licenses/by/4.0/). 